\title{
A (IN)VIABILIDADE DA NAVEGAÇÃO COMERCIAL PELO ARAGUAIA: UM SÉCULO DE DESAFIOS
}

\author{
Alcelides BATISTA ${ }^{1}$ \\ Instituto Educacional Santa Catarina - IESC \\ bathist@gmail.com
}

Resumo: $O$ objetivo desse artigo é apresentar um breve contexto histórico da navegação fluvial pelo rio Araguaia, considerando as ações políticas e administrativas tomadas em fins do século XVIII e ao longo do século XIX, no intuito de efetivar a comunicação e o comércio interprovincial Goiás-Pará. A partir do contexto histórico, pretende-se demonstrar também como os acidentes naturais existentes tornaram-se fatores limitantes para a implantação da navegação fluvial. Dessa forma, apresentamos relatórios de viajantes, estudos e memórias descritivas do período que registraram as condições de navegabilidade e as barreiras naturais que impediam ou limitavam a navegação ao longo do rio Araguaia.

Palavras-chave: Araguaia. Navegação. Goiás.

\begin{abstract}
The objective of this article is to present a brief historical context of river navigation along the Araguaia waters, considering the political and administrative actions taken in the late eighteenth century and throughout the nineteenth century in order to carry out communication and interprovincial trade through Goiás, Pará. From the historical context, it intends to also demonstrate how existing natural accidents have become limiting factors to the implementation of river navigation. Therefore, we present Traveler reports, descriptive studies and memories of the period that registered the conditions of navigability and natural barriers that prevented or limited the navigation along the Araguaia river.
\end{abstract}

Keywords: Araguaia. Navigation. Goiás.

\footnotetext{
${ }^{1}$ Professor Adjunto de Socilogia Jurídica, Dimensões Filosóficas, Sociológicas e Antropológicas, Políticas Aplicadas e Sociologia e Extensão Rural nos cursos de Direito, Enfermagem, Fisioterapia, Educação Física, Administração e Agronomia da Faculdade Guaraí - IESC.
} 


\section{Introdução}

A importância geográfica e econômica do Araguaia se justifica por suas dimensões, que, juntamente com o Tocantins, formam a maior bacia fluvial totalmente brasileira. Com sua nascente na Serra do Caiapó no sul de Goiás, o Araguaia percorre os estados de Mato Grosso, Tocantins e Pará, fazendo sua foz com o rio Tocantins na região da tríplice divisa entre Tocantins, Pará e Maranhão.

Segundo informações do Ministério dos Transportes (2014), o Araguaia possui extensão de $2.115 \mathrm{~km}$, destes $1.818 \mathrm{~km}$ são considerados de ótimo potencial para a navegação, estando dividido em três trechos: da sua foz até a cidade de Aruanã-GO $(1.472 \mathrm{~km})$, de Aruanã-GO até Barra do Garças-MT (288 km) e de Barra do Garças-MT até Baliza-GO (58 km).

Em relação às suas características físicas, o rio é dividido em Alto, Médio e Baixo Araguaia. O Alto Araguaia se desenvolve desde sua nascente até a cidade de Registro do AraguaiaMT, percorrendo uma distância de $450 \mathrm{~km}$ em um desnível de $570 \mathrm{~m}$. O segundo trecho (Médio Araguaia), vai desde Registro do Araguaia-MT até a cidade de Santa Isabel do Araguaia-PA, numa distância de $1505 \mathrm{~km}$ por um desnível de 185 m. Já o Baixo Araguaia compõe o trajeto de Santa Isabel do Araguaia-PA, até sua foz no rio Tocantins, um trecho de $160 \mathrm{~km}$ com desnível de apenas $11 \mathrm{~m}$, este último trecho apresenta os maiores obstáculos à navegação, composto por grandes cachoeiras, corredeiras e travessões (SANTOS, C. A., 2007).

$\mathrm{O}$ rio Araguaia pertence à Região Hidrográfica do Tocantins-Araguaia, que compreende uma área de $918.822 \mathrm{~km}^{2}$, correspondente a $11 \%$ do Território Nacional, abrangendo regiões de Goiás, Mato Grosso, Maranhão, Pará, Tocantins e Distrito Federal. Essa região está configurada no sentido Sul-Norte, com predominância dos biomas de Floresta Amazônica e Cerrado.

Sua área de drenagem atinge $377.000 \mathrm{~km}^{2}$, possuindo uma vazão média em torno de 6.100 $\mathrm{m}^{3} / \mathrm{s}$. O clima característico da região é o quente/semiúmido, tendo seus picos de cheia entre janeiro e maio, enquanto as menores vazões são registradas entre os meses de junho e setembro (AQUINO, S.; STEVAUX, J. C.; LATRUBESSE, E. M, 2005)².

\section{O Princípio da Navegação pelo Araguaia}

Devido à decadência da mineração na segunda metade do século XVIII, a província de Goiás estava mergulhada em uma profunda crise econômica tão intensa que viria a assolar a região por todo o século seguinte. Por ser uma região banhada por volumosos e extensos rios, o governo de Goiás viu a navegação fluvial e o comércio interprovincial como meio mais viável a ser adotado para retirar a província da estagnação.

\footnotetext{
${ }^{2}$ Este estudo é o resultado da análise de dados obtidos a partir de nove estações hidrológicas localizadas nos cursos do alto, médio e baixo Araguaia. As informações dão conta das vazões médias diária, mensal e anual, além de largura, profundidade e velocidade, coletadas entre os anos de 1970 e 1999.
} 
A situação econômica de Goiás é grave em consequência do gradativo esgotamento das minas. A ligação e o restabelecimento do comércio Goiás-Pará poderia vir a ser a solução para esse e muitos outros problemas. As relações comerciais passam a interessar aos governos das duas capitanias, principalmente as do Pará, porto de mar e centro distribuidor dos produtos europeus (DOLES, 1969, p. 254).

Entretanto, no auge da mineração, a Coroa Portuguesa ${ }^{3}$ havia proibido a navegação fluvial na tentativa de conter o contrabando do ouro, forçando, assim, sua retirada via terrestre e a passagem obrigatória pelas casas de fundição. Apenas em 1782, já com a mineração enfraquecida, a Coroa volta a permitir a livre circulação de embarcações na região, iniciando a partir de então, um conjunto de ações que visavam explorar a navegação, ocupar as margens e efetivar o comércio, principalmente pelos rios Araguaia e Tocantins.

Finalmente, em 1782, cai a proibição e a navegação do Tocantins e dos rios interiores passa a ser estimulada. No entanto, o longo período de interrupção da navegação deixou um saldo negativo representado pelo atraso do desenvolvimento daquela atividade e prejuízo para o povoamento das margens dos referidos rios (DOLES, 1969, p. 254).

Em face da enorme distância em relação aos grandes mercados consumidores, a administração da província de Goiás buscou alternativas para melhorar a comunicação com outras províncias e estimular o comércio interprovincial. As dificuldades econômicas despertaram o interesse dos governantes pelos grandes rios que banham a região, situando-os como primordiais para a comunicação entre as províncias de Mato Grosso, Goiás e Pará. Essa posição frente às dificuldades econômicas acabou resultando em diversas tentativas de efetivar a frequente navegação desses rios, em um cenário que perdurou por praticamente todo o século XIX, ora com maior, ora com menor intensidade.

A reabertura à circulação fluvial deu início a um novo cenário econômico, porém as cicatrizes deixadas por mais de quatro décadas de bloqueio à navegação e o descaso com a ocupação das margens já eram notáveis, evidenciando as dificuldades que viriam ao retomar esse processo. Diante da necessidade de estimular a produção e o comércio, os governos provinciais tinham nos rios a expectativa de solução de parte desse problema, superando os obstáculos do trânsito de mercadorias em larga escala e distância.

Assim, ainda no século XVIII, são incitadas as primeiras expedições de reconhecimento do rio Araguaia e de seu potencial uso para a navegação:

Por determinação do governador do Pará Dr. Francisco de Souza Coutinho, é feita a exploração do Araguaia e tenta-se travar relações com os indígenas da região. Ainda sob patrocínio do mesmo é organizada uma sociedade mercantil para explorar a navegação e o comércio entre Goiás e Pará. Em 5 de fevereiro de 1791,

\footnotetext{
${ }^{3} \mathrm{O}$ território brasileiro esteve submetido à condição de Colônia de Portugal até 1815, quando, através de um decreto, D. João VI o elevou à condição de Reino Unido a Portugal e Algarves.
} 
sob o comando do cabo Tomás de Souza Villa Real, parte uma expedição rumo a Vila Boa (DOLES, 1969, p. 254).

Villa Real retorna ao Pará com sua expedição apenas em 1793, entregando seu diário e apontamentos a Francisco de Souza Coutinho. Em carta enviada ao Ministro Martinho de Melo e Castro, em março do mesmo ano, Coutinho informa as condições de navegabilidade e propensão comercial com as províncias de Goiás e Mato Grosso, utilizando o rio Araguaia, conectando-se as capitais pelos rios Vermelho e das Mortes, respectivamente.

A dita exploração e reconhecimento, de que vou dar a conta não só correspondeu, mas excedeu, quanto a mim, que se pudera desejar; e se em toda a ocasião fora esta descoberta de grande interesse pelo notável acréscimo que deve produzir na cultura e no comércio de uma e outra capitania, na presente conjuntura ainda a considero mais importante pela facilidade dos prontos socorros, que esta pode receber d'aquela oferecendo-se a ocasião de os precisar. (...) tem por outra parte a incomparável vantagem de permitir o comércio e comunicação não só com aquela capital, senão também com os habitantes do Cuiabá (REAL, 1891, p. 401402).

Recomendando ao Ministro a ocupação e o cultivo das margens do rio, dando viabilidade à navegação:

Por estes motivos, independente do acréscimo da cultura que deve experimentar a da capitania de Goyaz encerrada até agora nos limites que prescrevia o consumo interior de seus habitantes, me parece de suma importância para o serviço de Sua Majestade que a navegação pelo dito rio Araguaya seja frequentada, povoando-se e cultivando-se as suas margens (REAL, 1891, p. 404).

Em carta do então governador da província de Goiás, Tristão da Cunha Menezes, ao comerciante Ambrozio Henriques, um dos responsáveis pela expedição de Villa Real, podemos observar que, nesse momento, o interesse do governo de Goiás era o de servir como entreposto comercial entre Pará e Mato Grosso, dando crédito ao projeto proposto por Coutinho:

Sr. Capitão Ambrozio Henriques. - O pardo Thomaz de Souza Villa Real, encarregado por $\mathrm{Vm}$. da exploração dos rios navegáveis desta capitania, por insinuação do Exmo. Sr. General d'esse Estado, me entregou com as cartas de S. Ex. $^{\text {a }}$ a que Vm. me dirigiu datada de 5 de fevereiro do ano pretérito: e suposto eu tenha procurado todos os meios de abreviar a referida expedição, ainda agora é que me é possível faze-lo seguir para essa cidade, onde de viva voz exporá a Vm. as vantagens que podem resultar do comercio à que $\mathrm{Vm}$. se propõe; os gêneros de mais consumo, os preços em que ordinariamente se reputam, a permutação que dos mesmos se poderá fazer com os produzidos no país; e finalmente a grande exportação que terão para as capitanias de Mato Grosso e Cuiabá, cujos comerciantes precisamente hão de passar por esta vila, e achando gêneros em que possam preencher as suas receitas, certamente os não irão buscar aos portos de mar. Queira Vm. contar sempre comigo para tudo quanto for do seu obsequio. 
Deus guarde a Vm. muitos anos. Vila Boa, 6 de outubro de 1792 (REAL, 1891, p. 411).

Embora tenha demonstrado interesse pelo comércio interprovincial, Menezes se isentou de propor investimentos para a navegação do Araguaia, limitando-se a dispor a capital de Goiás como intermediária comercial e de logística aos comerciantes que debandassem do Pará e do Mato Grosso.

Já no decorrer do século XIX, as províncias de Goiás e Pará demandaram recursos nessa empreitada, desde o financiamento de empresas de navegação até a construção de presídios ao longo do percurso. Durante esse período, na maioria das vezes, a região fora representada pelos documentos oficiais como longínqua, esquecida, mas que, ao mesmo tempo, vivia uma incessante luta para romper o isolamento através da navegação (CAVALCANTE, 2008).

As ações políticas apresentavam alta complexidade, a navegação não dependia somente de embarcações, necessitava ainda de mão-de-obra especializada, estrutura de apoio aos navegantes e produtos para comercialização. Para viabilizar a navegação, deveriam ser feitos grandes investimentos em estrutura, como portos e estaleiros, além da construção de presídios para apoio logístico aos navegantes, visto que uma viagem entre a Vila Boa e Belém, por exemplo, levava meses para ser realizada, carecendo às embarcações priorizar a carga de mercadorias em relação aos víveres.

Havia também a preocupação com os ataques dos nativos às embarcações, em seu roteiro, Villa Real anotou treze nações indígenas que habitavam a região do Araguaia. Em 1814, o Capitão Francisco de Paula Ribeiro, em sua viagem às fronteiras do Maranhão e de Goiás, acreditava que o ataque dos nativos era o principal motivo do fracasso da navegação pelo Araguaia até então, destacando a importância do rio principalmente para a Província de Goiás.

Ribeiro avaliava a situação na qual a região se encontrava, desde os aspectos geográficos até os econômicos da própria província, observando a grandiosidade do sertão ${ }^{4}$ goiano no espaço disposto entre os rios Araguaia e Tocantins, e apontando o quanto seria difícil a ocupação desse vasto território. Outros apontamentos fazem referência ao transporte fluvial de um modo geral, salientando que os únicos produtos necessários para os navegantes nas longas viagens eram sal, farinha, aguardente, pólvora, chumbo e anzóis, já que os demais víveres eram encontrados em abundância ao longo do rio.

Para Francisquinha L. Carvalho (2008, pp. 33-34), essa é a ideia de "Sertão ligado", onde "Os caprichos da natureza oferecem alimentação em abundância àqueles que o procuram", demonstrando o porquê da grande quantidade de nações indígenas habitando o vale do Araguaia.

Ao conjurar que o povoamento da região levaria de dois a três séculos, Ribeiro aparentava profetizar o que se ocorreu por quase todo o século XIX, que, em sua segunda metade, ainda parecia

\footnotetext{
${ }^{4}$ Segundo Janaína Amado (1995, p. 148), o termo fora amplamente utilizado por viajantes durante o século XIX como referência a "áreas extensas e afastadas do litoral, de natureza ainda indomada, habitadas por índios 'selvagens' e animais bravios, sobre as quais as autoridades portuguesas, leigas ou religiosas, detinham pouca informação e controle insuficiente".
} 
apenas um espelho da paisagem intocada, observada pelos primeiros navegantes, como salienta Taunay (1876, p. 19):

No estado de completo abandono em que jaz a imensa bacia cortada de aquele caudal, no pé desordenado dos presídios militares que são núcleos de vícios e desmando e nunca centros de onde possa irradiar população amiga do trabalho, cumpriria concomitantemente tratar de colonizar o ubérrimo vale, de atrair gente e prende-la à terra.

Taunay tinha plena convicção de que a viabilidade da navegação pelo Araguaia só aconteceria proporcionalmente à ocupação da região. Essa visão estratégica havia se manifestado nos gabinetes de governadores de Goiás desde as primeiras décadas do século, levando a materialização e investimentos ao setor. A administração da província estabelecia incentivos monetários às empresas de navegação, ao mesmo tempo em que procurava intensificar a ocupação das margens e o estabelecimento de núcleos de povoamento para garantir a oferta de produtos mercantis e a segurança da navegação.

\section{Ações e Intenções Políticas de Exploração do Araguaia}

Apesar de algumas viagens comerciais bem sucedidas entre Vila Boa e Belém terem sido realizadas, após a viagem de Villa Real em 1791, pouca coisa havia mudado em relação à exploração do rio Araguaia, com sua navegação permanecendo tímida por décadas, afastando a ideia de um fluxo comercial com o Pará por estas águas por um longo período.

Em 1811, o então governador de Goiás, Fernando Freire de Castilho, recebe ordem da Coroa para incentivar a navegação dos principais rios, povoando as margens, corrigindo os obstáculos naturais e resolvendo os problemas com os nativos. Para solucionar essas dificuldades, foi proposta a construção de presídios ${ }^{5}$, os quais, por falta de recursos, apenas dois conseguiram sair do projeto (DOLES, 1969).

Somente a partir da Independência, em 1822, é que políticas efetivas com o interesse em garantir a ocupação das fronteiras do "Brasil Central" foram aos poucos introduzidas pela administração imperial e, assim, houve real demonstração do domínio dessa região. Até a década de 1830, ocupar e navegar pelo rio Araguaia ainda permanecia basicamente no discurso dos presidentes da província de Goiás, mesmo que, muitas vezes, fosse apontada como solução para a recuperação econômica, como expôs, em 1836, o presidente Rodrigues Jardim, afirmando estar persuadido de que a navegação dos rios e a correspondência com o Pará trariam grande vantagem comercial.

Dois anos depois, Camargo Fleury (1838, p. 13) relatou o baixo retorno financeiro do norte da Província, reclamando que "os povos do Norte têm sido remissos na contribuição dos

\footnotetext{
${ }^{5}$ Os Presídios eram fortificações e/ou núcleos de povoamento construídos com a finalidade de ocupação territorial, defesa das fronteiras e fixação do poder governamental no interior. Ver: CARVALHO, Francisquinha Laranjeira. Fronteiras e conquistas pelo Araguaia - século XIX. Goiânia: Kelps, 2006.
} 
impostos" e apontou os problemas relacionados à navegação e ocupação das margens do Araguaia como resultado da violência dos povos Canoeiros, Xavante e Xerente contra os brancos.

Vale lembrar que, desde 1834, a questão indigenista estava sob a responsabilidade das Assembleias Provinciais, não havendo qualquer menção sobre o assunto nas leis imperiais. Esse fato levava à constante submissão ao Diretório Pombalino e ao controle absoluto do Estado sobre a população nativa (GIRALDIN, 2002).

Para Assis Mascarenhas (1839), a navegação e o comércio com o Pará seriam as únicas formas de reanimar os agricultores da Província, dando ênfase à produção de algodão, fumo, gado, café e açúcar. Considerava também que os principais entraves à navegação comercial eram os obstáculos naturais, o ataque dos nativos e a falta de mão de obra. Entretanto, fez observação à grande habilidade que os índios possuíam para a navegação, salientando a importância que teriam, caso fossem empregados como tripulantes nas embarcações.

Em seu relatório, Ramalho (1846, p. 10) apresentou a precariedade pela qual Goiás passava. Sobre o Araguaia, recomendou a criação de meios necessários para "promover a civilização dos indígenas e proporcionar os meios de realizar a já conhecida navegação d'este Rio", efetivando, assim, o comércio com outras províncias.

Dois são os grandes, e principais embaraços, que impedem a navegação do rio Araguaia: o primeiro é a falta de Povoações as margens deste Rio, que prestem aos navegantes os socorros indispensáveis de mantimentos, para que não se vejam obrigados a levarem seus Barcos quase inteiros carregados dos viveres precisos para tão longa viagem: o segundo é a agressão dos Selvagens, o que exige uma tripulação muito numerosa para a defesa dos comerciantes (RAMALHO, 1846, p. 18).

Sob o reinado de D. Pedro II, o Brasil buscou uma nova abordagem para a questão indígena: as decisões foram centralizadas na corte, sendo estabelecida a catequese e a civilização como mecanismos para inserir os nativos na sociedade. (GIRALDIN, 2002). Essa posição permitiu a entrada de missionários religiosos no país e que tiveram importante papel na composição da política de implantação dos presídios.

Convicto das vantagens que as características geográficas da província de Goiás proporcionavam, com seus grandes rios e campos férteis, Ramalho (1846) apresentou uma política de dupla missão: civilizar os índios e navegar o rio. Seu principal argumento centrava-se na possibilidade de estabelecimento comercial com o Pará em larga escala, realizado por meio da navegação. Convencendo os "capitalistas" da capital da Província a investir nesse empreendimento, arrecadou fundos para uma viagem experimental, a fim de explorar o comércio interprovincial com o Pará.

A viagem inaugural ficou a comando do então deputado Rufino Teotônio Segurado, que propôs a saída de Vila Carolina ${ }^{6}$, situada à margem direita do rio Tocantins, onde havia diversos

\footnotetext{
${ }^{6}$ Carolina-MA.
} 
gêneros de interesse comercial e remeiros de qualidade e baixo custo. Dessa forma, a descida até Belém seria realizada em sua totalidade pelo rio Tocantins e a viagem de volta pelo Araguaia.

O regresso teve sua saída do Porto do Pará ${ }^{7}$ em 19 de maio de 1847, atracando no Porto Thomaz de Souza $^{8}$ em 6 de fevereiro de 1848, trazendo mais de duas mil arrobas ${ }^{9}$ de mercadorias, dentre as quais, destacam-se o sal e o vinho (FLEURY, A. P., 1848, p. 19). Essa viagem foi considerada um ensaio, cujo propósito principal era o reconhecimento dos obstáculos e comodidades do rio e instituir a possibilidade da criação de uma empresa de navegação, que foi estabelecida através de um contrato de três anos.

Padua Fleury procurou resolver o problema de mão-de-obra na navegação solicitando ao frei Segismundo de Taggia, responsável pela catequese dos Xavantes, o envio de quarenta e cinco indígenas à capital para que lá pudessem ser "educados". Também ordenou a distribuição de roupas, fumo e ferramentas aos indígenas das margens do Araguaia na intenção de apaziguá-los e, consequentemente, facilitar a passagem dentro dos limites dominados por eles.

Eduardo Olimpio Machado (1850, p. 36) compartilhava dos mesmos ideais acerca da recuperação de Goiás, afirmando que "este desideratum só pode ser obtido pelo veículo da navegação fluvial". Durante seu governo foi construído, por ordem do Governo Imperial, o presídio de Santa Leopoldina, na confluência do rio Vermelho com o Araguaia, e ordenada a fundação de mais quatro: dois situados nas extremidades meridional e setentrional da Ilha do Bananal; um na Cachoeira Grande; e outro na região onde havia sido destruído o de Santa Maria, pelos indígenas, em 1813. Durante sua administração, também foi aberta uma picada conectando a Vila de Carolina ao Presídio de Cachoeira Grande, estimulando a comunicação entre os rios Araguaia e Tocantins por terra.

Na gestão de Silva Gomes (1851), o comércio do rio Araguaia novamente demonstrava acentuado enfraquecimento, com a empresa de navegação declarando prejuízo equivalente à metade de seu capital. Esse fato levou à criação de uma nova companhia, composta por quarenta acionistas e de sessenta ações no valor de cem mil réis cada.

Entretanto, em 1852, Gomes já mudaria seu discurso, dizendo que seria "mais acertado proteger de preferência a navegação do Tocantins" e recomendando a transferência dos presídios localizados nas margens do Araguaia para aquele rio.

A posição de Gomes foi compartilhada por seu sucessor, Francisco Mariani (1854, p. 28), que acreditava que a ocupação das margens do Araguaia deveria acontecer através da iniciativa dos próprios habitantes, com o decorrer do tempo, salientando que investir no povoamento era "disseminar a população tão escassa da Província", demonstrando não haver, naquele momento, nenhum incentivo à migração de pessoas de outras partes do país.

\footnotetext{
${ }^{7}$ Em Belém-PA.

${ }^{8}$ Rio Vermelho, próximo à antiga capital Vila Boa.

${ }^{9}$ No século XIX, uma arroba era equivalente a 32 arráteis ou 14,688 quilogramas. Ver: PEREIRA, Naiala Pires.

Medidas Tradicionais usadas em Goiás no Século XIX. Monografia (Graduação em História) Anápolis: UEG, 2009.
} 
A navegação comercial e a ocupação do Araguaia apresentavam-se, ano a ano, em constante retrocesso. Para Cruz Machado (1855, p. 64), “o futuro de sua navegação, comércio, civilização, riqueza, prosperidade enfim terá infelizmente de dormir ainda um longo sono, envolto no gélido manto da inércia e do abandono", o que seria comprovado nas administrações seguintes.

O assunto volta à tona somente no início da década de 1860, no governo de Alencastre, que apresentou, em seu relatório de 1862, um levantamento da navegabilidade do rio Araguaia, apontando oito travessões e três cachoeiras como os principais obstáculos naturais, havendo a possibilidade de navegação por vapores de até 21 palmos ${ }^{10}$ de calado no período de dezembro a junho. A partir desse momento, destaca-se a ideia da implantação da navegação a vapor, iniciando um novo ciclo na história do rio Araguaia, destacando-se a figura de Couto de Magalhães.

José Vieira Couto de Magalhães assume a presidência da Província de Goiás em 1863. Visionário e apaixonado pelo Araguaia, concentrou todos os esforços na implantação da navegação a vapor e na comunicação com as províncias de Mato Grosso e Pará. Nesse mesmo ano, Couto de Magalhães realiza uma viagem de reconhecimento do rio Araguaia, trazendo diversos apontamentos para a viabilização da navegação e do povoamento, reconhecendo que a recuperação econômica e o progresso da Província dependiam sistematicamente da ligação com outras províncias pelas vias fluviais.

A prosperidade desta província depende do Araguaia, esse imenso rio, que constitui uma verdadeira maravilha, já por sua beleza, já pela fertilidade das regiões que atravessa, já por oferecer uma navegação de cerca de 700 léguas. Para aí o goiano deve dirigir suas vistas, como o israelita as dirigia para a coluna de fumo que o guiava à Terra da Promissão. O futuro é grandioso com a navegação do Araguaia; sem ela, tudo é raquítico e mesquinho, como tem sido até o presente (MAGALHÃES, J. V. C., 1863, p. 41).

O sonho de Magalhães foi realizado em 29 de maio de 1868, durante a presidência de Gomes de Siqueira, quando foi inaugurada a tão esperada navegação a vapor do rio Araguaia. A cerimônia foi realizada em frente ao presídio de Leopoldina, contando com a presença de algumas autoridades e de Magalhães, responsável pela instalação da empresa de navegação.

É com o mais vivo prazer e verdadeira satisfação que trago ao vosso conhecimento o facto mais importante, e que tem de firmar a época mais notável da historia da província - a inauguração da navegação a vapor no Rio Araguaia, a qual teve lugar com as formalidades do estilo no dia 29 de Maio do corrente ano junto ao presídio de Santa Leopoldina, achando-se presentes muitas pessoas distintas desta cidade, que ali foram decretadamente para assistir a esse ato, e o Ex. presidente da província de Mato Grosso, Dr. José Vieira Couto de Magalhães, que mandando desarmar um pequeno vapor na flotilha de Mato Grosso, o fez transportar por terra até a colônia do Itacaiú no alto Araguaia, onde foi de novo reconstruído, e descendo águas abaixo, tendo a seu bordo o referido presidente, que pretendia seguir para o Rio de Janeiro, foi estacionar junto ao mencionado presídio de Santa

\footnotetext{
${ }^{10}$ A medida de um palmo correspondia a 22 centímetros (PEREIRA, N. P., 2009).
} 
Leopoldina, tomando no ato da inauguração o nome de Araguaia (SIQUEIRA, 1869, p. 4).

Em sua viagem de exploração, o vapor Araguaia percorreu a distância entre os presídios de Santa Leopoldina e Santa Maria em apenas treze dias, realizando a viagem de retorno em vinte e seis dias, sem nenhum incidente (SIQUEIRA, 1869).

Entretanto, em pouco tempo, as expectativas geradas pela navegação a vapor trouxeram à tona a realidade das dificuldades encontradas no rio, as viagens continuavam com custos e riscos altos, o que levou o governo provincial a diminuir o apoio da navegação pelo Araguaia e concentrálo no rio Tocantins. O presidente Ernesto Augusto Pereira (1870) acreditava que a navegação comercial pelo Araguaia seria viável somente em botes pequenos, já que os vapores eram muito grandes para manobrar entre corredeiras e travessões. Outro ponto destacado foi o fato de ainda existirem poucos pontos de apoio aos navegantes.

Com muitas dificuldades, a navegação permaneceu constante por um breve período, atingindo seu ápice durante a década de 1870. No relatório de 1875, Cícero de Assis deu notícia de um vapor que partiu de Leopoldina em direção ao Pará rebocando três botes, com um carregamento composto de 28 bestas, 400 couros de boi e 650 arrobas de cristal de rocha. Já no ano de 1878, foi assinado um contrato entre o empresário João José Corrêa de Moraes e o Império, no valor de quarenta mil réis, ficando estabelecidas seis viagens de ida e volta por ano entre Pará e Goiás (CRESPO, 1879).

O presidente Aristides de Souza Spindola (1880, p. 58) destacou que a navegação comercial via Araguaia possuía certa estabilidade e gerava lucros para a Província.

Hoje que a navegação tem melhores garantias; que emprega o vapor em uma grande extensão do rio; que é subvencionada e inspecionada pelo governo; que está mais conhecido o rio e há mais práticos para sua navegação; que desaparecerão quase todos os receios contra os selvagens; seria de grande proveito a organização de sociedades que se utilizassem dessa navegação, como já se fez antigamente. Parece que, a exemplo das passadas Assembleias, podíeis concorrer para a formação de tais sociedades.

Já no relatório entregue ao presidente da Província, Guilherme Francisco Cruz, em 1886, o empresário expõe as dificuldades em manter viagens regulares para o Pará. Segundo Moraes, havia muita dificuldade de travessia dos botes pelas cachoeiras, sendo comum a ocorrência de acidentes. No mesmo relatório, o empresário reclama da falta de pontos de apoio aos barqueiros durante o percurso das viagens por uma região a qual se referiu como "tão extensa zona deserta". Somando-se a isso, havia ainda o fato do risco de os botes serem saqueados pelos indígenas.

Todos esses fatores elevavam consideravelmente o custo do frete. Além disso, a obrigatoriedade imposta pelo contrato com o governo deixava a empresa dependente do comprometimento dos barqueiros que, pela falta de oferta de mão de obra, elevavam o preço do serviço prestado (CRUZ, 1886, A-N10). 
A partir desse momento a navegação entra em acentuado declínio, tendo como causas principais: a dificuldade do empresário em cumprir as cláusulas do contrato; a impossibilidade de fiscalização pelo governo; o abandono do serviço pelos oficiais devido à baixa remuneração e/ou atraso nos pagamentos; e a falta de pessoal qualificado para os serviços de conservação dos materiais flutuante e fixo.

Aos poucos, os investimentos do Araguaia foram sendo transferidos para o rio Tocantins, para onde estava voltada a atenção do governo goiano. Em fins da década de 1880, a empresa de navegação e os direitos de exploração do rio Araguaia foram transferidos para uma companhia estadunidense, que, incapacitada de executar o contrato, desiste da operação em 1888, encerrando suas atividades.

Assim, o ciclo da grande exploração da navegação pelo Araguaia no século XIX se encerra, com a região apresentando significativo crescimento somente no século seguinte, com a chegada de embarcações a motor e a construção estradas e ferrovias.

\section{Considerações Finais}

A navegabilidade de longa distância do rio Araguaia ainda permanece em acentuada discussão. Travessões, corredeiras e cachoeiras que irrompem no leito do rio impedem ou limitam a transposição de embarcações em vários trechos, o que possibilita somente a navegação regional, normalmente realizadas pelas populações ribeirinhas.

Desse modo, mesmo com os modernos equipamentos e técnicas de navegação, o Araguaia recebe atenção sistemática quanto à viabilidade de sua navegação, graças a suas características geográficas ímpares e, que, desde o século XVIII, são vistas com certa dicotomia: ora como impulsionadora para a ocupação e exploração de suas margens, ora como limitadora de sua conquista.

\section{Referências}

ALENCASTRE, José Januário da Gama. Relatório apresentado à Assembleia Legislativa de Goiás. Goiás: Tipografia Provincial, 1862.

AMADO, Janaína. Ponto de Vista: Região, Sertão, Nação. Rio de Janeiro: Estudos Históricos, n. 15, v. 8, p. 145-151, 1995.

AQUINO, S.; STEVAUX, J. C.; LATRUBESSE, E. M. Regime Hidrológico e Aspectos do Comportamento Morfohidráulico do Rio Araguaia. Revista Brasileira de Geomorfologia, ano 6, n. 2, p. 29-41, 2005. 
ASSIS, Antero Cícero de. Relatório apresentado à Assembleia Legislativa de Goiás. Goiás: Tipografia Provincial, 1875.

CARVALHO, Francisquinha Laranjeira. Fronteiras e conquistas pelo Araguaia - século XIX. Goiânia: Kelps, 2006.

CARVALHO, Francisquinha Laranjeira. Nas Águas do Araguaia: a navegação e a hibridez. cultural. Dissertação (Mestrado em História Cultural) Goiânia: UCG, 2008.

CAVAlCANTE, Maria do Espirito Santo Rosa. Um Rio que passou. Revista Mosaico, v. 1, n. 2 , p. 157-162, 2008.

CRESPO, Luiz Augusto. Relatório apresentado à Assembleia Legislativa de Goiás. Goiás: Tipografia Provincial, 1879.

CRUZ, Guilherme Francisco. Relatório apresentado à Assembleia Legislativa de Goiás. Goiás: Tipografia Provincial, 1886.

DOLES, Dalísia Elizabeth Martins. A Ligação Centro-Norte pela Via Araguaia-Tocantins no Período Colonial. Campinas: V Simp. Nac. dos Prof. de História - ANPUH (p. 252-262), 1969.

FLEURY, Antônio de Pádua. Relatório apresentado à Assembleia Legislativa de Goiás. Goiás: Tipografia Provincial, 1848.

GIRALDIN, Odair. Catequese e civilização. Os capuchinhos "entre" os "selvagens" do Araguaia e Tocantins. Belém: Bol. do Mus. Paraense Emílio Goeldi (série Antropologia), v. 2, n. 18, 2002.

MACHADO, Antônio Cândido da Cruz. Relatório apresentado à Assembleia Legislativa de Goiás. Goiás: Tipografia Provincial, 1855.

MACHADO, Eduardo Olympio. Relatório apresentado à Assembleia Legislativa de Goiás. Goiás: Tipografia Provincial, 1850.

MAGALHÃES, José Vieira Couto de. Relatório apresentado à Assembleia Legislativa de Goiás. Goiás: Tipografia Provincial, 1863.

MARIANI, Francisco. Relatório apresentado à Assembleia Legislativa de Goiás. Goiás: Tipografia Provincial, 1854.

PEREIRA, Ernesto Augusto. Relatório apresentado à Assembleia Legislativa de Goiás. Goiás: Tipografia Provincial, 1870.

RAMALHO, Joaquim Ignácio. Relatório apresentado à Assembleia Legislativa de Goiás. Goiás: Tipografia Provincial, 1846. 
REAL, Thomas de Souza Villa. Viagem de Thomaz de Souza Villa Real pelos rios Tocantins, Araguaia e Vermelho. (2a Ed.) Revista Trimestral do Instituto Histórico e Geográfico Brasileiro, tomo XI. Rio de Janeiro: Tipografia Nacional, p. 401-444, 1891.

SIQUEIRA, João Bonifácio Gomes de. Relatório apresentado à Assembleia Legislativa de Goiás. Goiás: Tipografia Provincial, 1869.

SPINDOLA, Aristides de Souza. Relatório apresentado à Assembleia Legislativa de Goiás. Goiás: Tipografia Provincial, 1880.

TAUNAY, Alfredo de Escragnolle. A Província de Goyaz. (Exposição Nacional de 1875) Rio de Janeiro: Typographia Nacional, 1876. 